the strengths and weaknesses of university-industry collaborations that are in operation. Interaction with our own Associate Members is to be intensified. The national societies of EPS are urged to exert pressure in their own countries on governments, university authorities and industry to take action along the lines indicated and to treat the subject as both serious and urgent.

Copies of the full report are available, free of charge, on request from the EPS Secretariat in Geneva.

\section{Helping Developing Countries}

The International Centre for Theoretical Physics in Trieste has renewed its appeal for help in supplying libraries of universities in developing countries with back issues of journals and copies of physics books. Previous appeals have produced an encouraging response, but the need is great and continual. Little improvement is to be seen in the funding available for scientific information and frequently inflation and balance of payments' difficulties cause a deterioration in real terms so that the information deficit steadily rises even if a nucleus has, at one time, been established.

Colleagues in the more fortunate countries do not have illimited resources but they are, in the main, able to keep pace with current literature - if they can find somewhere to put it. Many physicists and libraries find their shelves packed with old journals and text books that they cannot bear to throw away, primarily, because they are still in good condition. These are what ICTP would like to direct towards the needy.

There is a similar market for redundant laboratory apparatus. Schools and universities accumulate equipment which has become obsolete because of changes in curricula, changes in teaching style, etc. but which could find a second life if only there were a means of directing it towards those in want.

This exists: For journals, books and apparatus, ICTP has established a coordination centre which will inform potential donors of the acceptability of their offer and the place to which the material concerned should be sent. If you have in physics and mathematics any textbooks you no longer use, volumes of journals that are taking up valuable space, or apparatus that is only gathering dust, write to:

Professor H.R. DALAFI

International Centre for Theoretical Physics POB 586

1-34100 Trieste

giving him details of what you are prepared to donate. He will then explain what should be done.

\section{International Physics}

\section{Impressions of the EPS Symposium on International Facilities for Physics Research}

As a follow-on to the Symposium on European Great Projects held in Rome from 26-27 March 1979, a Symposium on International Facilities for Physics Research was held from 21-23 March 1983 in Copenhagen and Ris $\emptyset$ prior to the meeting of the EPS Council. Sponsored also by the American Physical Society, the Risø National Laboratory (celebrating the 25th anniversary of its foundation through the initiative of Niels Bohr) and the Novo Foundation, and organised by a committee chaired by A.R. Mackintosh, the Symposium aimed at reviewing major facilities (existing and planned) for physics research throughout the world.

\section{Nuclear and Particle Physics}

At the opening session, contrasting pictures were painted of the diffuse situation in nuclear physics and the highly organised state of high energy physics where not only are the physicists mobilised on a regional basis, but even the major regions have complementary rather than competitive programmes. In the $1950 \mathrm{~s}$, much of the fundamental research in nuclear structure was made using Van de Graafs and small cyclotrons in university laboratories; in the ' 60 s tandem accelerators and isochronous cyclotrons came into operation and the inhigh resolution spectroscopy. By the '70s, with the upgrading of tandems and the growth in importance of heavy ion accelerators and electron linacs the centre of gravity had moved into specialised centres and, with the demand for machines of increased intensity and energy, collaboration at the international level is now becoming necessary. This trend is already in evidence. troduction of germanium detectors allowed
Machines that will be required before long include electron accelerators of a few $\mathrm{GeV}$ and high intensity (see Laget J.M. Europhysics News, May 1983), heavy ion accelerators capable of imparting up to 30 $\mathrm{GeV}$ per nucleon, as well as accelerators for the production of high intensity kaon and antiproton beams. Superconducting technology is becoming increasingly important, but the principles of acceleration remain traditional for the present, and novel methods will be required if continued progress is to be made. In comparison with high energy physics projects, the size of machines for nuclear physics research will remain modest, and a form of cooperation in which international use is made of a national facility, would seem to be more appropriate than another CERN.

CERN has now a multiplicity of interconnected accelerators and storage rings capable of a great diversity of operation. The most important facility is the $450 \mathrm{GeV}$ proton machine with an intensity of nearly $3 \times 10^{13}$ protons/pulse. It can be operated as a $270-270 \mathrm{GeV}$ proton-antiproton collider achieving luminosities of $5 \times 10^{28} \mathrm{~cm}^{-2}$ $\mathrm{S}^{-1}$ and the dramatic discoveries of the $\mathrm{W}$ and $Z^{\circ}$ particles provide triumphant proof of its research potential. The $p-p$ Intersecting Storage Rings with a centre of mass energy of $62 \mathrm{GeV}$ and luminosities of up to $1.4 \times 10^{32} \mathrm{~cm}^{-2} \mathrm{~s}^{-1}$ will be closed down at the end of this year to provide resources for the electron-positron ring LEP which will start as a $50-50 \mathrm{GeV}$ machine, then with superconducting RF cavities will be stretched to $80-80 \mathrm{GeV}$ and afterwards to $125-125 \mathrm{GeV}$. At the other end of the energy scale, a wide range of experiments is being conducted on low energy antiproton beams (momentum $0-600 \mathrm{MeV} / \mathrm{c}$ ) of very low momentum spread.
Table 1 - High Energy Physics Facilities Available in the USA

\begin{tabular}{|c|c|c|c|c|c|}
\hline Laboratory & & Device & Energy, GeV & $\begin{array}{l}\text { Intensity/ } \\
\text { Luminosity, } \\
\mathrm{cm}^{-2} \mathrm{~s}^{-1}\end{array}$ & Remarks \\
\hline BNL & AGS & p-synch. & 30 & $10^{13 / 2 \mathrm{~s}}$ & fixed target \\
\hline Fermilab & - & p-synch. & 400 & $2 \times 10^{13 / 10 s}$ & fixed target \\
\hline \multirow[t]{3}{*}{ SLAC } & - & e-linac & 33 & $10^{14} \mathrm{e} / \mathrm{s}$ & $\begin{array}{l}\text { fixed target } \\
\text { primarily e, } \gamma\end{array}$ \\
\hline & SPEAR & $\mathrm{e}^{+}-\mathrm{e}^{-}$collider & $3.5 /$ beam & $1.5 \times 10^{31}$ & ( 2 interaction regions) \\
\hline & PEP & $\mathrm{e}^{+}-\mathrm{e}^{-}$collider & $14.5 /$ beam & $2.2 \times 10^{31}$ & (6 interaction regions) \\
\hline \multirow[t]{2}{*}{ Cornell } & CESR & $\mathrm{e}^{+}-\mathrm{e}^{-}$collider & $5.2 /$ beam & $1.5 \times 10^{31}$ & ( 2 interaction regions) \\
\hline & & & & 500 (nb-day) $^{-1}$ & \\
\hline LANL & LAMPF & $\mathrm{p}$-linac & $0.8 \mathrm{GeV}$ & $10^{15} / \mathrm{s}$ & fixed target \\
\hline
\end{tabular}

